\title{
FORMAÇÃO PARA O TRABALHO NO SUS: UM OLHAR PARA O NÚCLEO DE APOIO À SAÚDE DA FAMÍLIA E SUAS CATEGORIAS PROFISSIONAIS
}

\author{
QUALIFICATION FOR WORKING AT THE SUS: A LOOK INTO THE FAMILY HEALTH SUPPORT \\ CENTER AND ITS PROFESSIONAL CATEGORIES
}

\author{
Josemar Ramos Nunes Junior \\ Cinthia Rodrigues de Vasconcelos \\ Ana Cecilia Primavera Arantes \\ Curso de Fisioterapia \\ Universidade Federal de Pernambuco
}

\author{
Contato \\ Josemar Ramos Nunes Junior \\ Rua Francisco Lacerda, 90 \\ Edifício Bosque da Várzea - Bl. B, Ap.102 - Várzea \\ Recife-PE \\ CEP: 50741-150 \\ E-mail:j.marnunes@hotmail.com
}

\section{RESUMO}

Introdução: A Estratégia Saúde da Família (ESF) ampliou a cobertura assistencial e evidenciou a necessidade de agregar profissionais de distintas áreas para assegurar a integralidade na atenção à saúde. O Núcleo de Apoio à Saúde da Família (NASF) surgiu, assim, trazendo a necessidade de que o modelo de ensino em saúde vigente no Brasil esteja de acordo com os princípios do SUS. Objetivo: Analisar a percepção dos acadêmicos do último período dos cursos de graduação da UFPE que atuam no NASF sobre os impactos de suas formações na aquisição de competências e saberes para atuar no Núcleo. Método: Trata-se de um estudo transversal, envolvendo 68 acadêmicos de cursos de Graduação da UFPE (Farmácia, Fisioterapia, Fonoaudiologia, Nutrição, Psicologia, Serviço Social e Terapia Ocupacional). Na coleta de dados, utilizou-se um questionário semiestruturado, construído pelos pesquisadores. Resultados: Segundo os acadêmicos, os currículos contemplaram disciplinas que possibilitaram um olhar para a atuação na Atenção Primária à Saúde, porém a preparação teórica e prática foram consideradas insuficientes para a atuação com segurança na área. Diante disso, $66 \%$ dos alunos não se sentem preparados para planejar e desenvolver ações de saúde estrategicamente no NASF, e apenas $25 \%$ dos acadêmicos buscaram uma formação extracurricular para obter maior capacitação para atuar no NASF, reafirmando que as poucas experiências existentes na graduação não estão dando o suporte adequado para direcionar os acadêmicos na busca dos conhecimentos que possibilitam atuar com segurança na Saúde Pública. Conclusões: A percepção dos acadêmicos mostra a necessidade de mudanças curriculares para uma melhor atuação profissional no SUS, bem como a manutenção de disciplinas específicas sobre o SUS e fortalecimento de espaços extracurriculares.

Palavras-chave: Saúde Pública. Atenção Primária à Saúde. Universidades. Educação. 


\section{ABSTRACT}

Introduction: The Family Health Strategy (FHS) enhanced the assistance coverage and highlighted the need of gathering professionals from multiple areas into its teams to make sure health attention is provided in full. The Family Health Support Center (FHSC) emerged, thus, bringing the need to adjust the health educational model in Brazil to the principles of the current healthcare system in Brazil (SUS). Objective: Assessing the perception of senior undergraduates from the Federal University of Pernambuco (UFPE), which have been practicing at the FHSC, as for the impact of their higher educational background when acquiring competences and knowledge to perform at the FHSC. Methodology: It is a cross-sectional study involving 68 undergraduate students at UFPE from the schools of pharmacology, physiotherapy, speech therapy, nutrition, psychology, social work and occupational therapy. Data gathering used a semi-structured questionnaire developed by the authors. Results: According to the students, the courses syllabuses involved subjects that enabled a view to the work at Primary Health Care, but the theoretic and practical preparations were considered insufficient for an assured performance in the area. Considering that, $66 \%$ of the students do not feel prepared to strategically plan and develop actions in health at the FHSC, and only $25 \%$ of them sought extracurricular training, in order to gather more technical capacity to perform at the FHSC, corroborating the fact that the few experiences present during undergraduation are not giving adequate support to lead the students in their search for the knowledge that can enable them to act safer in the area of Public Health. Conclusions: The perception of the students show the necessity of changes in syllabuses aiming a better professional performance at the SUS, as well as the maintenance of subjects specific to the SUS and the strengthening of extracurricular spaces.

Keywords: Public Health. Primary Health Care. Universities. Education.

\section{INTRODUÇÃO}

$A^{c}$ Constituição Federal Brasileira de 1988, ao instituir o Sistema Único de Saúde (SUS), garante como direito, a todos os cidadãos, o acesso integral, universal e igualitário à saúde e, conforme o art. 200, inciso III, define que cabe ao SUS a importante função de ordenar a formação de trabalhadores na área da saúde ${ }^{1}$.

Ao garantir serviços de saúde à sociedade, o SUS, a partir da Atenção Primária à Saúde (APS), apresenta uma possibilidade de desenvolvimento de ações de promoção, prevenção e recuperação da saúde, de forma integral e contínua. Foi criado pelo Ministério da Saúde (MS), em 1991, o Programa de Agentes Comunitários de Saúde (PACS), investindo maciçamente na educação em saúde. Em 1994, a implantação do Programa de Saúde da Família, posteriormente denominado Estratégia Saúde da Família (ESF), reestruturou a Atenção Básica com a família passando a ser considerada a unidade de intervenção².

A ESF ampliou a cobertura assistencial, possibilitando a identificação de novas necessidades de saúde. Evidenciou-se, então, a necessidade de ampliação das Equipes de Saúde da Família (EqSF), agregando a elas profissionais de distintas áreas, a fim de assegurar a integralidade na atenção à saúde para solucionar problemas de ordem política, social, cultural e econômica para fortalecer o SUS. Dessa forma, por meio da Portaria $\mathrm{N}^{\circ}$. 154, de 2008, atualizada na portaria $N^{\circ} 3.124$, de 2012, foi criado o Núcleo de Apoio à Saúde da Família (NASF), que tem como objetivo ampliar a abrangência e o escopo das ações de Atenção Básica, bem como sua eficácia e eficiência ${ }^{3,4}$.

As ações múltiplas propostas pelo NASF requerem um novo olhar do profissional no campo ético-político e no que concerne ao seu processo de trabalho, exercitando a integralidade e a interdisciplinaridade. No entanto, a formação acadêmica desses profissionais não abrange as premissas necessárias para a atuação de acordo com os princípios do SUS e diretrizes do NASF, necessitando ser aprendido no cotidiano da produção, na prestação de serviços de saúde e na imersão no trabalho coletivo ${ }^{5}$.

O modelo de ensino superior em saúde vigente no Brasil privilegia, predominantemente, a expansão do ensino clínico, especialmente em hospitais, e enfatiza a pesquisa biológica, o que tem origem no século XX, como forma de superar a era empírica do ensino médico, supervalorizando a especialização. Esse modelo foi criado a partir do Relatório Flexner, produzido nos Estados Unidos em 1910, orientando a mudança do currículo das escolas de medicina, o que conduziu a prática para a superespecialização, influenciando a formação acadêmica das graduações em saúde até os dias de hoje ${ }^{6}$. Esse modelo estimula um olhar acadêmico reducionista, reservando pequeno espaço, se algum, para as dimensões social, psicológica e econômica da saúde ${ }^{7}$.

Com o intuito de nortear a elaboração dos perfis curriculares dos cursos de graduação em saúde no Brasil, tem-se as Diretrizes Curriculares Nacionais (DCN), que foram publicadas em 2002 com o obje- 
tivo de estimular a inserção precoce e progressiva do estudante no SUS, fornecendo aos acadêmicos o conhecimento e compromisso com a realidade de saúde do seu país e sua região ${ }^{1,8}$. A substituição do currículo mínimo pelas diretrizes curriculares permitiu que os currículos propostos pudessem construir perfis acadêmicos e profissionais com competências, habilidades e conteúdos condizentes com uma abordagem contemporânea de formação, no entanto, há 14 anos, as DCN das profissões envolvidas no NASF não sofreram qualquer alteração, proporcionando poucos avanços na educação superior em saúde ${ }^{9}$.

Antes da elaboração das DCN, já havia na área de saúde movimentos por mudanças na graduação. A Política de Educação Permanente, o Programa Nacional de Reorientação da Formação Profissional em Saúde (Pró-Saúde), lançado em 2005, o AprenderSUS, o Vivências e Estágios na Realidade do Sistema Único de Saúde (VER-SUS), protagonizado pela articulação entre instituições de ensino, sistema de saúde, organizações populares e Rede UNIDA, são exemplos de mobilizações que têm envolvido múltiplos atores objetivando a integração ensino-serviço, visando à reorientação da formação profissional que conta com protagonismo de entidades, organizações e o Governo Federal ${ }^{9,10,12}$.

Apesar de alguns avanços, o perfil dos egressos não é adequado para uma atuação na perspectiva da atenção integral à saúde e de práticas que contemplem ações de promoção, proteção, prevenção, atenção precoce, cura e reabilitação ${ }^{10}$. Cada vez mais, os conteúdos especializados permeiam os currículos das graduações, multiplicando-se disciplinas, conteúdos e tempos. Perdeu-se o conhecimento generalista das ações em saúde e substituiu-se cada vez mais o subjetivismo da relação profissional da saúde-paciente pela objetividade tecnológica das ciências da saú$\mathrm{de}^{12,13}$. A maneira como são estruturados e funcionam os processos de formação e de práticas profissionais em saúde configura um quadro de raciocínio propositivo e avaliativo comprometido com muitos tipos de interesse, exceto o dos usuários ${ }^{14}$.

A formação acadêmica representa hoje um papel de suma importância para a construção de um SUS democrático, equitativo e eficiente ${ }^{11}$. Assim, este trabalho tem como objetivo analisar a percepção dos acadêmicos do último período dos cursos de graduação da Universidade Federal de Pernambuco (UFPE), cujas profissões atuam no NASF, sobre o impacto de sua formação acadêmica na aquisição das competências e saberes específicos para atuação no NASF. 


\section{MÉTODO}

$T$ rata-se de um estudo quantitativo do tipo corte transversal, desenvolvido nas Coordenações dos Cursos de Graduação em saúde da UFPE, no período de março a dezembro de 2015. Este estudo faz parte de um projeto de pesquisa intitulado "Percepção sobre as competências e saberes da formação acadêmica das profissões envolvidas no NASF da Cidade do Recife: desafios para o planejamento e gestão", do "Programa de Pesquisa para o SUS: gestão compartilhada em saúde - PPSUS - REDE", vinculado à Fundação de Amparo à Ciência e Tecnologia do Estado de Pernambuco (FACEPE).

Esta pesquisa teve aprovação do Comitê de Ética em Pesquisa com Seres Humanos por meio do parecer CAEE nº 07414112.8.1001.5208). O início do estudo apenas ocorreu após permissão das coordenações dos cursos atuantes no NASF: Farmácia, Fisioterapia, Fonoaudiologia, Nutrição, Psicologia, Serviço Social e Terapia Ocupacional, com tamanho amostral de 68 voluntários. Os demais cursos não foram incluídos por pertencerem à equipe mínima da estratégia da saúde da família (como Medicina, Odontologia e Enfermagem) ou pelo fato de não estarem ligados ao NASF na Secretaria de Saúde da Cidade do Recife, como é o caso do curso de Educação Física, que está vinculado ao Programa Academia da Cidade.

Adotaram-se como critérios de inclusão: que o aluno deveria estar concluindo seu curso de graduação no semestre letivo da coleta de dados; que a Coordenação de Curso fornecesse as possibilidades para a coleta de dados, visto que na maioria dos cursos os acadêmicos estavam realizando estágio curricular obrigatório fora do campus da UFPE. Assim, o Curso de Fonoaudiologia não foi inserido nesta pesquisa porque que não houve a possibilidade de aplicação do questionário em tempo hábil, conforme cronograma proposto.
Para a coleta de dados, utilizou-se um questionário semiestruturado, construído pelos próprios pesquisadores, que continha informações que possibilitaram a construção da percepção dos estudantes sobre as competências e os saberes obtidos em sua formação acadêmica para atuação no NASF.

O questionário possuía 39 perguntas quantitativas que incluíam informações sociodemográficas, além de indagações em relação ao conhecimento teórico das legislações norteadoras do SUS e do NASF. Ademais, apresenta questões relacionadas com a estrutura curricular voltadas para este fim. Do total de perguntas, 25 questões estavam relacionadas com a formação acadêmica e foram utilizadas para traçar o perfil acadêmico. Entretanto, 3 questões foram excluídas porque 16 participantes ( $24 \%$ da amostra) não as responderam, totalizando 22 questões.

O preenchimento de todos os questionários foi feito pelos próprios acadêmicos, individualmente, em salas de aula da UFPE, na maioria das vezes após atividades presenciais de disciplinas que estivessem cursando. Antes do preenchimento, os acadêmicos foram esclarecidos sobre os objetivos da pesquisa, e os que concordaram em participar assinaram o Termo de Consentimento Livre e Esclarecido. A média de duração do preenchimento foi de 25 minutos, tendo sido realizado mediante a presença dos pesquisadores.

Após coleta, os dados foram tabulados em um banco de dados no Programa Excel®, versão 2016 (Microsoft, Microsoft Excel, Washington, USA), e conferências foram realizadas pelos pesquisadores. Para análise dos dados, não foi feita distinção entre os cursos. As variáveis foram apresentadas em valores percentuais. Os dados foram analisados no software SPSS 20.0 para Windows (IBM Corp. Armonk, EUA). 


\section{RESULTADOS}

oram inseridos neste estudo 68 acadêmicos, dos
159 regularmente matriculados nos cursos partici-
pantes da pesquisa, o que corresponde a $42,77 \%$
do total. Dos sete cursos que poderiam ter sido incluí-
dos, apenas o curso de Fonoaudiologia não fora inse-
rido nesta amostra por problemas de logística na coor-
denação do curso. A média de idade dos estudantes foi
de 23 anos, e $79,4 \%$ eram do sexo feminino (Tabela 1).

Tabela 1. Características amostrais de estudantes da Universidade Federal de Pernambuco participantes do estudo, Recife, 2015

\begin{tabular}{|c|c|c|c|c|c|}
\hline $\begin{array}{l}\text { CURSOS } \\
\text { DE GRADUAÇÃO }\end{array}$ & $\begin{array}{l}\text { Total } \\
\text { de Matrículas }\end{array}$ & $\begin{array}{l}\text { n } \\
\% \text { das matrículas }\end{array}$ & $\begin{array}{l}\text { SEXO } \\
\text { Feminino } \\
\text { n (\%) }\end{array}$ & $\begin{array}{l}\text { Masculino } \\
\text { n (\%) }\end{array}$ & $\begin{array}{l}\text { MÉDIA DA IDADE } \\
\text { (anos) }\end{array}$ \\
\hline Farmácia & 21 & $9(42,85 \%)$ & $6(66,7 \%)$ & $3(33,3 \%)$ & $22 \pm 2,35$ \\
\hline Fisioterapia & 25 & 17 (68\%) & $14(82,4 \%)$ & $3(17,6 \%)$ & $23 \pm 1,72$ \\
\hline Nutrição & 26 & $13(50 \%)$ & $12(92,3 \%)$ & $1(7,7 \%)$ & $23 \pm 3,96$ \\
\hline Psicologia & 15 & $6(40 \%)$ & $2(66,7 \%)$ & $4(33,3 \%)$ & $23 \pm 1,60$ \\
\hline Serviço Social & 63 & $8(12,69 \%)$ & $6(75 \%)$ & $2(25 \%)$ & $23 \pm 8,24$ \\
\hline Terapia Ocupacional & 24 & $15(62,5 \%)$ & $14(93,3 \%)$ & $1(6,7 \%)$ & $23 \pm 2,16$ \\
\hline Total & 159 & $68(42,77 \%)$ & $54(79,4 \%)$ & $13(20,6 \%)$ & $23 \pm 3,78$ \\
\hline
\end{tabular}

${ }^{*}$ A diferença numérica no quantitativo de pessoas incluídas na pesquisa aconteceu por dificuldades de comunicação com a coordenação do curso na obtenção das informações necessárias ou por falta de uma disciplina que agrupasse a turma inteira em um determinado dia da semana. Nesse último caso, o diálogo com os Diretórios Acadêmicos foi importante para a identificação dos acadêmicos.

A amostra estudada, quando perguntada "Quando você se formar, o currículo em vigência no seu curso é o mesmo que você ingressou na IES?", respondeu da seguinte forma: Farmácia, 100\% não; Fisioterapia, 64,7\% não; Nutrição, 15,4\% não; Psicologia, 100\% não; Serviço Social, 12,5\% não; e Terapia Ocupacional, $26,7 \%$ não. $\mathrm{Na}$ análise geral do grupo, 48,52 \% dos estudantes responderam não.

Quanto à análise da percepção dos acadêmicos em relação à estrutura curricular de seus cursos para atuação no NASF (tabela 2), verifica-se que $67,64 \%$ dos entrevistados, independentemente do curso no qual es- tivesse matriculado, disseram não ter tido preparação teórica suficiente nas disciplinas cursadas para atuar na APS, aumentando esse percentual para $83,82 \%$ quando perguntados sobre a preparação prática.

Quando perguntados sobre sentirem-se preparados para planejar estrategicamente as ações de saúde que deverão desenvolver no NASF, $66,17 \%$ dos estudantes responderam não; $83,82 \%$ dos acadêmicos sentem a necessidade de que ocorra alguma mudança na estrutura curricular do seu curso, para que haja uma melhor formação do profissional que irá atuar no SUS (tabela 2). 
Entre os acadêmicos entrevistados, cerca de $73 \%$ não buscaram formação extracurricular, apesar de $77,94 \%$ terem afirmado ter participado de experiências interdisciplinares. Dos acadêmicos entrevistados (25\%) que buscaram formação extracurricular para obter uma maior capacitação para atuar no NASF (tabela 2), 8,8\% foram por meio de projetos de extensão, $7,4 \%$ por meio de projeto do MS e disciplinas não obrigatórias e 1,5\% foi obtida mediante cursos a distância. Quando se observam os cursos separadamente, verifica-se que os acadêmicos de Nutrição e Serviço Social foram os que mais buscaram formação extracurricular (tabela 2).

Tabela 2. Percepção dos acadêmicos da Universidade Federal de Pernambuco em relação à estrutura curricular de seus cursos para atuação no Núcleo de Apoio à Saúde da Família (NASF), Recife, 2015.

PERGUNTAS
SIM

n $\%$

$22 \quad 32,35 \%$
NÃO

n $\%$

"Você sente que teve preparação teórica suficiente, nas disciplinas cursadas, para atuar na APS?"

"Você sente que teve preparação prática suficiente, nas disciplinas cursadas, para atuar na APS?"

$10 \quad 14,70 \%$

$57 \quad 83,82 \%$

"Você sente necessidade de que ocorra alguma mudança na estrutura curricular do seu curso para que haja uma melhor formação do profissional que irá atuar no SUS?”*

$57 \quad 83,82 \%$

$10 \quad 14,70 \%$

"Você conseguirá colocar em prática, durante sua atividade profissional no NASF, os princípios e diretrizes que regem o SUS?”*

32

$47,1 \%$

$31 \quad 45,6 \%$

"Você se sente preparado para planejar estrategicamente as ações de saúde que deverá desenvolver junto ao NASF?"

$18 \quad 26,47 \%$

$45 \quad 66,17 \%$

"Você buscou uma formação extracurricular para obter uma maior capacitação para atuar no NASF?” 17 $25 \%$ $50 \quad 73,52 \%$

"Você teve em sua vida acadêmica alguma experiência interdisciplinar?" 53 $77,94 \%$ $12 \quad 17,64 \%$

${ }^{*}$ As respostas cuja soma não resultou no $n=68$ são justificadas pela presença de respostas nulas nessas questões 
Como mostra a tabela 3 , quando perguntados se "Durante a graduação, a estrutura curricular contemplou disciplinas que tinham como objetivo específico transmitir conhecimentos que possibilitassem sua atuação profissional na APS?", $82,35 \%$ dos acadêmicos disseram que sim. Destes, os cursos de Farmácia $(100 \%)$, Serviço Social $(87,5 \%)$ e Terapia Ocupacional $(86,7 \%)$ foram os que mais contemplaram disciplinas que abordavam temáticas relacionadas com a atenção básica.

Tabela 3. Características da estrutura curricular dos cursos de graduação da Universidade Federal de Pernambuco que atuam no Núcleo de Apoio à Saúde da Família (NASF), Recife, 2015.

\begin{tabular}{|c|c|c|c|c|c|c|}
\hline & \multicolumn{2}{|c|}{$\begin{array}{l}\text { "A estrutura curricular } \\
\text { contemplou disciplinas que } \\
\text { tinham como objetivo específico } \\
\text { transmitir conhecimentos que } \\
\text { possibilitassem sua atuação } \\
\text { profissional na APS?" }\end{array}$} & \multicolumn{2}{|c|}{$\begin{array}{l}\text { "Na sua vida acadêmica, } \\
\text { você participou, juntamente } \\
\text { com profissionais da Prefeitura, } \\
\text { das atividades rotineiras do } \\
\text { NASF?” }\end{array}$} & \multicolumn{2}{|c|}{$\begin{array}{l}\text { "Na sua vida acadêmica, } \\
\text { você participou, juntamente } \\
\text { com profissionais da Prefeitura } \\
\text { das atividades rotineiras das } \\
\text { USFs, independentemente de estar } \\
\text { acompanhado ou não de docente?" }\end{array}$} \\
\hline & $\begin{array}{l}\text { SIM } \\
\text { n (\%) }\end{array}$ & $\begin{array}{l}\text { NÃO } \\
\text { n (\%) }\end{array}$ & $\begin{array}{l}\text { SIM } \\
\text { n (\%) }\end{array}$ & $\begin{array}{l}\text { NÃO } \\
\text { n (\%) }\end{array}$ & $\begin{array}{l}\text { SIM } \\
\text { n (\%) }\end{array}$ & $\begin{array}{l}\text { NÃO } \\
\text { n (\%) }\end{array}$ \\
\hline Farmácia & $9(100)$ & $0(0)$ & $2(22,2)$ & $7(77,8)$ & $4(44,4)$ & $5(55,6)$ \\
\hline Fisioterapia & $12(70,6)$ & $5(29,4)$ & $8(47,1)$ & $9(52,9)$ & $15(88,2)$ & $2(11,8)$ \\
\hline Nutrição & $10(76.9)$ & $3(23,1)$ & $11(84,6)$ & $2(15,4)$ & $8(61,5)$ & $5(38,5)$ \\
\hline Psicologia & $5(83,3)$ & $1(16,7)$ & $1(16,7)$ & $5(83,3)$ & $2(33,3)$ & $4(66,7)$ \\
\hline Serviço Social & $7(87,5)$ & $1(12,5)$ & $0(0)$ & $7(87,5)$ & $2(25)$ & $6(75)$ \\
\hline $\begin{array}{l}\text { Terapia } \\
\text { Ocupacional }\end{array}$ & $13(86,7)$ & $2(13,3)$ & $5(33,3)$ & $10(66,7)$ & $11(73,3)$ & $4(26,7)$ \\
\hline TOTAL & $56(82,35)$ & $12(17,64)$ & $27(39,70)$ & $40(58,82)$ & $42(61,76)$ & $26(38,23)$ \\
\hline
\end{tabular}

Com relação à experiência em comunidades, este estudo mostrou que $57,4 \%$ dos entrevistados tinham, em seu curso, 1 disciplina com esse objetivo, $25 \%$ deles afirmaram ter de 2 a 4 disciplinas e $17,6 \%$ não possuíam nenhuma disciplina com essa experiência. Das experiências em comunidades, 69,1\% delas aconteceram vinculadas à ESF, e 14,7\% aconteceram de forma isolada. 
Mais da metade dos entrevistados, $66,2 \%$ da amostra, possuía de 2 a 4 disciplinas em sua estrutura curricular que instruíam e direcionavam, direta ou indiretamente, para a atuação na APS, enquanto $29,4 \%$ dos entrevistados possuíam apenas 1 disciplina, e $2,9 \%$ não possuíam nenhuma disciplina com essa intencionalidade. Em nenhuma das questões foi perguntado sobre o fator obrigatório ou eletivo das disciplinas.

A tabela 4 traz o nível de conhecimentos dos acadêmicos acerca dos princípios e diretrizes do SUS, suas dificuldades e suas importâncias para a atuação profissional.

Tabela 4. Princípios e diretrizes do SUS de maior dificuldade de concretização e maior relevância na prática profissional, segundo a percepção de acadêmicos da Universidade Federal de Pernambuco participantes do estudo, Recife, 2015.

\author{
PRINCÍPIOS E \\ DIRETRIZES DO SUS \\ Universalidade \\ Equidade \\ Integralidade \\ Regionalização \\ Descentralização \\ Participação Popular \\ Não sei \\ Não respondeu \\ Total
}

\begin{tabular}{cc|cc}
\multicolumn{2}{c|}{ DIFÍCIL CONCRETIZAÇÃO } & MAIOR RELEVÂNCIA \\
$\mathbf{N}$ & $\mathbf{\%}$ & $\mathbf{N}$ & $\%$ \\
10 & 14,7 & 8 & 11,8 \\
18 & 26,5 & 14 & 20,6 \\
16 & 23,5 & 16 & 23,5 \\
2 & 2,9 & 0 & 0 \\
8 & 11,8 & 2 & 2,9 \\
7 & 10,3 & 2 & 2,9 \\
0 & 0 & 22 & 32,4 \\
7 & 10,3 & 4 & 5,9 \\
68 & 100 & 68 & 100
\end{tabular}

Em relação à percepção acadêmica em relação às atividades desempenhadas na Unidade de Saúde da Família (USF), no NASF, verificou-se que a presença de uma disciplina específica de Saúde Pública e/ou Saúde Coletiva na estrutura curricular foi a principal potencialidade apresentada pelos acadêmicos com relação a possibilitar uma atuação mais eficaz no NASF durante suas formações $(39,70 \%)$, conforme tabela 5. O Estágio Curricular na área, com $11,76 \%$ das respostas, foi a segunda potencialidade mais presente nos currículos dos cursos de graduação em saúde da UFPE. A prática na USF e a não existência de um instrumento que possibilitasse esse debate dentro dos currículos apareceram em poucas respostas.

Em relação às áreas estratégicas de atuação do NASF, mais de $60 \%$ dos entrevistados não souberam responder qual seria a de maior facilidade $e$ a de maior dificuldade para exercer sua atividade profissional. As respostas dos demais entrevistados confirmam a realidade do desconhecimento sobre as áreas estratégicas do NASF, visto que as respostas fornecidas não são compatíveis para a resposta correta esperada, tais como matriciamento, visitas domiciliares, acolhimento, entre outras (tabela 5). 
Tabela 5. Percepção dos acadêmicos da UFPE sobre atividades desempenhadas na USF, no NASF, bem como as áreas estratégicas de atuação do NASF, Recife, 2015.

\section{PERGUNTAS}

Atividade rotineira com profissionais das USFs da Prefeitura que mais se identificou

\section{PRINCIPAIS RESPOSTAS}

Palestras

Acolhimento

Visitas domiciliares

Atividade em grupos

Prática do Estágio

Atenção farmacêutica

PET-saúde

Elaborar Projeto Terapêutico Singular

Não soube responder

$\begin{array}{ll}\text { n } & \text { \% } \\ 1 & 1,47 \\ 3 & 4,41 \\ 12 & 17,64 \\ 5 & 7,35 \\ 2 & 2,94 \\ 1 & 1,47 \\ 1 & 1,47 \\ 1 & 1,47 \\ 16 & 23,52\end{array}$

Atividade em grupos

Visitas domiciliares

Discussão de casos

Práticas Integrativas

PET-saúde

Acolhimento

Não soube responder
5,88

10,29

2,94

1,47

1,47

1,47

25
Dentre as áreas estratégicas de atuação do NASF, eleja uma em que você tenha a maior facilidade de exercer sua atividade profissional
Matriciamento

Atividades de Educação em saúde

Visitas domiciliares

Prática em Saúde Mental

Atendimento em grupos

Acolhimento

Assistência farmacêutica

Atendimento compartilhado

Não soube responder

Interdisciplinaridade

Intersetorialidade

Dentre as áreas estratégicas de atuação do

NASF, eleja uma em que você tenha a mais dificuldade de exercer sua atividade profissional Gerência

Atendimento compartilhado

Discussão de casos

Planejamento de ações em saúde

Elaborar Projeto Terapêutico Singular

Não sei responder
2,94

2,94

1,47

2,94

5,88

1,47

5,88

1,47

64,70

1,47

1,47

1,47

1,47

1,47

1,47

1,47

$1 \quad 1,47$

\section{DISCUSSÃO}

O acadêmicos dos cursos de graduação da UFPE, que atuam no NASF, sentem necessidade que ocorra alguma mudança na estrutura curricular de seus cursos para que haja uma melhor formação do profissional que irá atuar no SUS.

Esta pesquisa teve aprovação do Comitê de Ética eApesar das propostas de mudança dos currículos por meio das DCN terem sido construídas desde 2002, aproximadamente metade dos acadêmicos dos 6 cursos da UFPE envolvidos neste estudo re- lataram estar cursando o perfil curricular correspondente ao perfil de ingresso na universidade. Como a duração média desses cursos é de 4 a 5 anos para sua conclusão, constata-se que o dinamismo na organização das disciplinas é algo difícil de ser concretizado, supondo-se que isso ocorra devido à resistência na construção das grades curriculares, seja por falta de participação estudantil nos processos de construção do currículo, pela falta de preparação docente em áreas sociais do cuidado em saúde ou pela pouca carga horária oferecida pelo curso. 
Sobre a ótica dos estudantes, a estrutura curricular contempla disciplinas que possibilitam a formação para a atuação na APS, porém a preparação teórica e prática foram consideradas insuficientes para possibilitar uma atuação com segurança na área. Isto pode ser explicado pelo fato de que, no treinamento prático tradicional, o ensino em saúde segrega teoria e prática, fragmentando o aprendizado, e se observa uma hierarquização do conhecimento, ao passo que ocorre uma enorme resistência às mudanças. Sair do hospital para trabalhar em outros cenários representa um grande desafio ${ }^{13}$

Neste estudo, constatou-se que os acadêmicos participaram, juntamente com profissionais da Prefeitura, de atividades rotineiras das USFs, entretanto, com relação às atividades rotineiras do NASF, apenas $39,70 \%$ tiveram acesso a essa experiência. Isso parece contraditório, visto que os acadêmicos são aproximados de práticas profissionais que não são específicas de suas competências e habilidades, logo não há o estímulo para a identificação do aluno com a profissão para a qual está sendo formado. Como reflexo, verificou-se que $66 \%$ dos alunos não se sentem preparados para planejar estrategicamente as ações de saúde que deveriam desenvolver no NASF.

A experiência em comunidades em pelo menos uma disciplina durante a graduação esteve presente em mais da metade dos entrevistados, sendo a grande maioria das experiências vinculadas à ESF. Assim, faz-se necessário entender que a aprendizagem em serviço é uma proposta de tomar os problemas da realidade como objeto da aprendizagem, da docência e da produção de conhecimentos, que se concretizariam como práticas articuladas, inscritas na produção de serviços ou na produção social da saú$\mathrm{de}^{12}$. As iniciativas comprometidas com a relevância social da universidade e dos processos de formação no campo da saúde têm historicamente procurado articular a universidade e os serviços, buscando ligar os espaços de formação aos diferentes cenários da vida real e dos cuidados em saúde ${ }^{17}$.

A extensão universitária também tem contribuído muito no rearranjo do processo acadêmico, pois vem possibilitando o comprometimento da universidade com as demandas sociais. Este estudo mostrou que dos acadêmicos que buscaram uma formação extracurricular para obter uma maior capacitação para atuar no NASF (25\%), 8,8\% foram por meio de projetos de extensão e $7,4 \%$ por meio de projetos do MS e disciplinas não obrigatórias. Ao defender o argumento de que a formação do estudante não deve se limitar aos ensinamentos em sala de aula, a extensão universitária abre caminhos para ampliar as transformações curriculares na tentativa de construir conhecimentos que venham ao encontro das reais necessidades da população ${ }^{18}$.
Complementando essa necessidade, a inserção do estudante desde o início do curso em atividades práticas, como extensão e projetos vinculados ao MS, propicia um campo potencial e necessário, condizente com a realidade vivenciada pela população brasileira, possibilitando uma clínica ampliada e a aplicação efetiva de ações preventivas e promotoras da saúde coletiva. Tais processos educacionais requerem um papel docente diferenciado para a melhor condução dessa formação, um papel de mediação fundamental para relação teoria e prática que seja capaz de orientar e facilitar um processo de aprendizagem em que o estudante possa expor suas ideias, dúvidas, sentimentos, conhecimentos e valores ${ }^{13}$.

Para a determinação das necessidades sociais em saúde, é necessário levar em consideração a interdisciplinaridade na construção das grades curriculares para além dos setores educação e saúde ${ }^{15}$. 0 presente estudo mostrou que $77,94 \%$ dos acadêmicos vivenciaram experiências interdisciplinares em suas vidas acadêmicas, o que é de extrema relevância para uma formação profissional direcionada à resolução dos problemas de saúde e que conduza o processo de formação acadêmica de forma a interagir com áreas políticas, sociais, culturais, econômicas, demográficos, somando-se ao conhecimento científico, tecnológico e ético da formação e aos aspectos administrativos e contribuições didático-pedagógicas para permitir a construção de um perfil profissional competente para atuar no SUS, em toda sua complexidade, garantindo o direito constitucional à saúde ${ }^{15}$.

Nessa perspectiva, é essencial garantir que o estudante esteja envolvido nos debates que permeiam a sociedade e que possa participar também da construção das políticas públicas direcionadas às mulheres, ao público LGBT, à população negra, em situação de rua, juventude, bem como populações do campo, das florestas e das águas, por meio do entendimento de que o controle social nasce da ideia da construção coletiva dos direitos e deveres e que a universidade representa em um espaço de disputa e transformação social.

Aproximadamente metade da amostra desse estudo também não se sentiu preparada para colocar em prática os princípios e diretrizes que regem o SUS durante sua atividade profissional no NASF. Grande parte dos acadêmicos $(32,4 \%)$ não soube eleger qual princípio do SUS é o mais relevante, o que reforça a importância da Universidade em trazer discussões mais densas com relação aos princípios do SUS, bem como a observação destes na prática. Entretanto a Equidade e a Integralidade apareceram entre os princípios do SUS com maior relevância e como os que possuem maior dificuldade de concretização.

Dos acadêmicos entrevistados, especificamente em relação ao NASF, $64,70 \%$ e $75 \%$, respectivamente, 
não souberam informar qual a área estratégica do Núcleo que considera ter mais facilidade ou mais dificuldade para atuação profissional, o que demonstra ainda a falta de abordagem estratégica dessa temática dentro das disciplinas existentes em cada estrutura curricular.

Segundo as Diretrizes do NASF (2009), o Núcleo é composto de nove áreas estratégicas: Saúde Mental, Saúde da criança, do adolescente e do jovem, Alimentação e Nutrição, Serviço Social, Reabilitação e saúde integral da pessoa idosa, Saúde da mulher, Assistência farmacêutica, Atividade física e Práticas Integrativas e Complementares, sendo necessário atuação multiprofissional, em conjunto com as EqSF, de Fisioterapeutas, Terapeutas Ocupacionais, Psicólogos, Nutricionistas, Fonoaudiólogos, Assistentes Sociais, Farmacêuticos e Educadores Físicos ${ }^{16}$.

As atividades em grupo e as visitas domiciliares foram a atividades rotineiras mais frequentes, tanto na USF quanto no NASF, citadas pelos acadêmicos. Visitas domiciliares, embora apresentem uma dimensão biopsicossocial do usuário conforme sua realidade e território existencial, também podem sinalizar um caráter mais clínico do cuidado, visto que as demais práticas educativas, preventivas e de promoção foram pouco realizadas pelos próprios estudantes. Nesse sentido, é importante ressaltar que o trabalho na APS vai além da visita domiciliar clínica-assistencial e enfatizar a importância do trabalho coletivo, para além das tecnologias leve-duras e duras ${ }^{5}$.

Como aparelho ideológico do Estado, a reprodução das desigualdades sociais se torna uma das funções da universidade que contribui para a manutenção da estrutura capitalista retratada, principalmente por meio do projeto político neoliberal fundamentado na desresponsabilização do Estado com relação à garantia dos direitos sociais, focalizando a assistência na defesa da privatização e incentivando a liberalização da educação superior à iniciativa privada. Dessa maneira, garantir o controle da sociedade mediante o movimento estudantil, conselhos profissionais, movimentos sociais, serviços de saúde e governo federal é de suma importância para garantir a qualidade dos cursos oferecidos e chamar a atenção das instituições formadoras para sua responsabilidade com a realidade de saúde brasileira e com o egresso nela formado ${ }^{15,19}$.

Para que o trabalho interdisciplinar aconteça nos moldes que o NASF propõe, faz-se necessária uma revisão crítica acerca dos processos formativos e educativos implantadas pelas Instituições de Ensino Superior (IES). A inserção dos profissionais na Atenção Básica à Saúde, especificamente do NASF, necessita não somente de uma reorganização para uma atuação mais eficaz, mas também de uma ampliação dos investimentos acadêmicos. A parceria entre os Ministérios da Educação e da Saúde é indissociável para a formação de trabalhadores, desde a formação inicial até processos de educação permanente ${ }^{20}$

A construção de grades curriculares que englobem espaços de debate sobre o SUS nas universidades públicas, como previsto pela $\mathrm{DCN}$, enfrenta o grande desafio de vencer o pensamento biomédico, curativista e centrado na doença fortemente proposto pelo Relatório Flexner. Na educação superior, sob justificativa de ampliar da oferta, o projeto neoliberal incentivou e promoveu a liberalização do ensino à iniciativa privada, sem incentivar a ampliação de instituições federais. O sucateamento do SUS, a privatização dos serviços de saúde e a abertura de cursos à distância são fatores preocupantes, pois limitam, de forma considerável, o aprendizado em serviço, distorcendo o caráter formativo do SUS e da Atenção Básica ${ }^{19}$. Assim, a percepção dos acadêmicos dos cursos de saúde de instituições privadas pode apresentar respostas diferentes e destoantes da percepção dos acadêmicos que podem participar de variados projetos de extensão universitária, bem como ter acesso a práticas interdisciplinares e disciplinas eletivas em uma universidade pública.

A formação deve buscar desenvolver condições de atendimento às necessidades de saúde das pessoas e das populações, da gestão setorial e do controle social em saúde, redimensionando o desenvolvimento da autonomia das pessoas até a condição de influência na formulação de políticas do cuidado ${ }^{21}$.

\section{CONSIDERAC̣ÕES FINAIS}

$F^{\circ}$ oi evidenciado que apesar de existirem disciplinas específicas abordando a temática da Saúde Pública e Coletiva e de ocorrerem experiências em comunidades vinculadas ou não à ESF, a percepção dos acadêmicos ainda mostra a necessidade de mudanças na estrutura curricular de seus respectivos cursos para favorecer uma melhor atuação profissional no SUS. Faz-se necessário sensibilizar as instâncias cabíveis sobre a importância da multidisciplinariedade, bem como a articulação entre as instâncias que compõe o Quadrilátero da Formação (instituição de ensino, serviços de saúde, a gestão e os dispositivos de controle social) na criação de práticas no SUS que envolvam os diversos níveis de atenção e complexidade do sistema.

Os resultados apresentados nesta pesquisa forneceram evidências científicas para estudos mais aprofundados que possam envolver aspectos variados da formação de profissionais na área da saúde e que poderão ser utilizadas no planejamento, identificando desafios que perpassam a gestão da formação voltada para o trabalho no SUS, auxiliando que órgãos responsáveis pela regulação das diferentes profissões também possam intervir, nas IES, na construção de seus projetos pedagógicos. 


\section{Referências}

1. Haddad AE, Morita MC, Pierantoni CR, Brenellil SL, Passarella T, Campo FE. Formação de profissionais de saúde no Brasil: uma análise no período de 1991 a 2008. Rev. Saúde Pública. 2010;44(3):383-393.

2. Nascimento DD, Oliveira MAC. Reflexões sobre as competências profissionais para o processo de trabalho nos Núcleos de Apoio à Saúde da Família. Mundo saúde (Impr.) . 2010;34(1):92-96.

3. Formiga NF, Ribeiro KS. Inserção do Fisioterapeuta na Atenção Básica: uma Analogia entre Experiências Acadêmicas e a Proposta dos Núcleos de Apoio à Saúde da Família (NASF). Rev. Bras. Ciênc. Saúde . 2012;16(2):113-122.

4. Barbosa EG, Ferreira DLS, Furbino SAR. Experiência da fisioterapia no Núcleo de Apoio à Saúde da Família em Governador Valadares, MG. Fisioter. mov. 2010;23(2):323-330.

5. Souza MC, Bomfim AS, Souza JN, Franco TB. Fisioterapia e Núcleo de Apoio a Saúde da Família: conhecimento, ferramentas e desafios. Mundo saúde (Impr.) . 2013;37(2):176-184.

6. Silva AG, Alves CA. Modelos tecnoassistenciais em saúde: o debate no campo da saúde coletiva. In Morosini MV. (Org). Modelos de atenção e a saúde da família. Rio de Janeiro, p. 27-41, 2007. Disponível em:<http://www.retsus.fiocruz.br/upload/publicacoes/pdtsp_4.pdf> Acesso em: 24 dez.2013

7. Pagliosa FL, Ros MA. O Relatório Flexner: Para o bem e para o mal. Rev. bras. educ. méd. 2008;32(4):492-499.

8. Brasil. Ministério da Educação. Conselho Nacional de Educação. DCN dos Cursos de Graduação em Fisioterapia, Fonoaudiologia e Terapia Ocupacional. Parecer CNE/CES n 1210. Diário Oficial da União, Brasília. 2001. Disponível em: <http://portal.mec.gov.br/cne/arquivos/pdf/pces1210_01.pdf>. Acesso em: 21 dez. 2013.

9. Recine E, Gomes RC, Fagundes AA, Pinheiro ARO, Teixeira BA, Sousa JS, Toral N, Monteiro RA. A formação em Saúde Pública nos cursos de graduação de Nutrição no Brasil. Rev. nutr. 2012;25(1):21-33.

10. Pires ACT, Braga TM. O psicólogo na saúde pública: formação e inserção profissional. Temas psicol. 2009;17(1):151-162.

11. Gil CR. Formação de recursos humanos em saúde da família: paradoxos e perspectivas. Cad. saúde pública. 2005;21(2):490-498.

12. Rego STA. Além do discurso de mudança na educação médica: processos e resultados. Interface Comun. Saúde Educ. 2003;7(12):169-70.

13. Ferreira RC, Fiorini VM, Crivelaro E. Formação Profissional no SUS: o Papel da Atenção Básica em Saúde na Perspectiva Docente. Rev. bras. educ. méd. 2010; 34(2): 207-215.

14. Brasil, Ministério da Saúde. Secretaria de Gestão do Trabalho e da Educação na Saúde. Departamento de Gestão da Educação na Saúde. AprenderSUS: o SUS e os cursos de graduação da área da saúde. Brasília, 20 p, 2004.

15. Rocha VM, Caldas MAJ, Araújo FRO, Ragasson CAP, Santos MLM, Batiston AP As diretrizes curriculares e as mudanças na formação de profissionais fisioterapeutas. Fisioter. Bras. 2010;11(5):4-8.

16. Brasil, Ministério da Saúde. Secretaria de Atenção à Saúde. Departamento de Atenção Básica. Cadernos de Atenção Básica, Brasília, n. 27, 160 p, 2009. Disponível em: <http://bvsms.saude.gov.br/ bvs/publicacoes/caderno_atencao_basica_diretrizes_nasf.pdf>. Acesso em: 15 jan. 2014

17. Albuquerque VS, Gomes AP, Rezende CHA, Sampaio MX, Dias OV, Lugarinho RM. A integração ensino-serviço no contexto dos processos de mudança na formação superior dos profissionais da saú de. Rev. bras. educ. méd. 2008;32(3):356-362.

18. Novo LF. Um olhar sob o prisma da responsabilidade social da universidade e a função da EAD como agente responsabilizador da IES perante a sociedade. IX Colóquio Internacional sobre Gestão Universitária na América do Sul, Florianópolis, 2009.

19. Bispo Júnior JP. Formação em fisioterapia no Brasil: reflexões sobre a expansão do ensino e os modelos de formação. Hist. ciênc. saúde-Manguinhos. 2009;16(3):655-668.

20. Bolzan DP, Isaia SM, Maciel AM. Formação de professores: a construção da docência e da atividade pedagógica na Educação Superior. Rev. Diálogo Educ. 2013;13(38):49-68.

21. Ceccim RB, Feuerwerker LCM. O quadrilátero da formação para a área da saúde: ensino, gestão, atenção e controle social. Physis (Rio J.). 2004;14(1):41-65. 